\title{
Respiratory mechanics in patients with tense cirrhotic ascites
}

\author{
R. Duranti*, G. Laffi**, G. Misuri++, D. Riccardi**, M. Gorini+, M. Foschi**, \\ I. Iandelli*, R. Mazzanti**, M. Mancini*, G. Scano*, P. Gentilini**
}

Respiratory mechanics in patients with tense cirrhotic ascites. R. Duranti, G. Laffi, G. Misuri, D. Riccardi, M. Gorini, M. Foschi, I. Iandelli, R. Mazzanti, M. Mancini, G. Scano, P. Gentilini. @ERS Journals Ltd 1997.

ABSTRACT: Lung volumes are decreased by tense ascites and increase after large volume paracentesis (LVP). The overall effect of ascites and LVP on the respiratory function is poorly understood.

We studied eight cirrhotic patients with tense ascites before and after LVP. Inspiratory muscle force (maximal transdiaphragmatic pressure $\left(P_{\mathrm{di}}, \mathrm{max}\right)$, and the lowest pleural pressure $(P \mathrm{pl}, \mathrm{min}))$ was assessed while the patients were seated. Rib cage and abdominal volume displacements, as well as pleural and gastric pressures were measured during quiet breathing while the patients were supine.

$P$ di,max and $P_{\mathrm{pl}, m i n}$ were normal and did not change after LVP (from 84.2 \pm 19.7 to $85.2 \pm 17.0 \mathrm{cmH}_{2} \mathrm{O}$ and from $68.3 \pm 19.7$ to $74 \pm 15.9 \mathrm{cmH}_{2} \mathrm{O}$, respectively). The abdominal contribution to the generation of tidal volume was greater than that of the rib cage ( 79 vs $21 \%$ ), a pattern which did not change after LVP (73 and $27 \%$ ). Before LVP, tidal swings both of pleural pressure $(P \mathrm{pl}, \mathrm{sw})$ and transdiaphragmatic pressure $(P$ di,sw $)$ were large $\left(15.3 \pm 4.3\right.$ and $18.5 \pm 3.9 \mathrm{cmH}_{2} \mathrm{O}$, respectively) and the load on inspiratory muscles was increased as a consequence of elevated dynamic elastance of the lung $(E \mathbf{l}, \mathrm{dyn})\left(\mathbf{1 1 . 4} \pm 2.6 \mathrm{cmH} \mathrm{O}_{2} \cdot \mathrm{L}^{-1}\right)$ and ("intrinsic") positive endexpiratory pressure $(\mathrm{PEEP})\left(4.3 \pm 3.5 \mathrm{cmH}_{2} \mathrm{O}\right)$. $\mathrm{LVP}$ reduced the load on the inspiratory muscles, as shown by the significant decrease in $P \mathrm{pl}, \mathrm{sw}\left(10.6 \pm 2.0 \mathrm{cmH}_{2} \mathrm{O}\right)$, $P_{\text {di,sw }}\left(12.8 \pm 3.0 \mathrm{cmH}_{2} \mathrm{O}\right), E$,dyn $\left(10.0 \pm 2.0 \mathrm{cmH}_{2} \mathrm{O} \cdot \mathrm{L}^{-1}\right)$ and PEEPi $(1.1 \pm 1.3 \mathrm{cmH}, \mathrm{O})$. The amount of fluid removed was closely related to changes in Ppl,sw and PEEPi.

We conclude that the strength of the inspiratory muscles is normal or reduced in seated cirrhotic patients. In the supine position, tense ascites results in an increase in lung elastic load and development of positive end-expiratory pressure, with a consequent overload and increased activation of inspiratory muscles. Large volume paracentesis decreases overloading and activation, but does not change the strength of the inspiratory muscles.

Eur Respir J 1997; 10: 1622-1630.
*Section of Pneumology, Istituto di Medicina Interna ed Immunoallergologia and ** Istituto di Medicina Interna, Università di Firenze, Firenze, Italy. +Unità di Terapia Intensiva Polmonare, Azienda Ospedaliera di Careggi, Firenze, Italy, ++Pro-Juventute Don Gnocchi Foundation Pozzolatico, Firenze, Italy.

Correspondence: R. Duranti

Istituto di Medicina Interna ed Immunoallergologia

Università degli Studi di Firenze

Viale Morgagni 85

50134 Firenze

Italy

\section{Keywords: Cirrhosis}

dynamic elastance

inspiratory muscle strength

large volume paracentesis

positive end-expiratory alveolar pressure

Received: October 211996

Accepted after revision March 191997

Supported by grants from the Ministero dell'Università e della Ricerca Scientifica e Tecnologica of Italy, and by the Italian Liver Foundation, Florence, Italy.
Although tense ascites has been reported to decrease lung volumes, and large volume paracentesis (LVP) to increase them [1-3], the overall effect of ascites and LVP on the respiratory function is poorly understood. In patients with ascites, ABELMANN et al. [1] observed decreased lung volumes, rapid shallow breathing and increased resting oxygen consumption; paracentesis caused an increase in lung volumes, and a reduction both of respiratory frequency and resting oxygen consumption. According to AbELMANn et al. [1], these alterations were due to the increased intra-abdominal pressure that was transmitted to the chest, causing increase in pleural pressure, elevation and relative fixation of the diaphragm, and increased stiffness of the chest wall: the movements of a more rigid thoracic cage required an increased work of breathing. If this hypothesis is correct, overloading and, thereby, increased activation of inspiratory muscles should be observed in ascitic patients. These aspects of the respiratory function have not been defined [2-4]. To obtain further insight into this issue, we carried out the present study, in which the mechanical characteristics of the respiratory system were investigated in patients with tense ascites before and after LVP.

\section{Methods}

\section{Subjects}

Eight patients ( 7 males and 1 female; mean age $57 \pm 8$ yrs, range 43-71 yrs) with tense cirrhotic ascites, consecutively admitted to the Istituto di Medicina Interna of the University of Florence between October 1993 and March 1995, were studied. Tense ascites was defined as "a tight distension of abdominal wall consequent to the presence of a high intra-abdominal pressure in cirrhotic patients with large ascitic fluid accumulation evoking a strong sense of abdominal painful tension". Criteria for inclusion in the study were: 1) presence of tense ascites; 2) no clinical or laboratory evidence of 
Table 1. - Anthropometric and clinical data of patients with cirrhotic ascites

\begin{tabular}{|c|c|c|c|c|c|c|c|c|c|}
\hline No. & Sex & Age & $\begin{array}{c}\text { Weight } \\
\mathrm{kg}\end{array}$ & $\begin{array}{l}\text { Height } \\
\mathrm{cm}\end{array}$ & $\begin{array}{l}\text { Smoking } \\
\text { pack-yrs }\end{array}$ & Diagnosis & $\begin{array}{l}\text { Child-Pugh } \\
\text { class }\end{array}$ & $\begin{array}{l}\text { Amount of } \\
\text { fluid removed } \\
\text { L }\end{array}$ & $\begin{array}{c}\text { Weight } \\
\text { decrease } \\
\text { kg }\end{array}$ \\
\hline 1 & M & 71 & 76 & 168 & 40 & HBV & B & 11.2 & 11.0 \\
\hline 2 & M & 43 & 87 & 174 & 17 & $\mathrm{HBV}, \mathrm{HCV}$ & $\mathrm{C}$ & 5.1 & 5.5 \\
\hline 3 & M & 59 & 92 & 166 & 10 & CRYPT & $\mathrm{C}$ & 13.0 & 15.1 \\
\hline 4 & M & 66 & 74 & 164 & 24 & $\mathrm{HCV}$ & $\mathrm{C}$ & 6.8 & 6.7 \\
\hline 5 & M & 55 & 85 & 170 & 0 & HBV & $\mathrm{C}$ & 6.5 & 7.0 \\
\hline 6 & $\mathrm{~F}$ & 56 & 62 & 150 & 0 & $\mathrm{HCV}$ & $\mathrm{C}$ & 4.1 & 6.0 \\
\hline 7 & M & 53 & 106 & 183 & 36 & $\mathrm{HCV}$ & $\mathrm{C}$ & 3.5 & 5.5 \\
\hline 8 & M & 55 & 72 & 160 & 45 & $\mathrm{HCV}$ & $\mathrm{C}$ & 7.2 & 9.0 \\
\hline
\end{tabular}

Pts: patients; M: male; F: female; HBV: hepatitis B virus; HCV: hepatitis C virus; CRYPT: cryptogenetic cirrhosis.

other systemic diseases, infection or fever, recent gastrointestinal bleeding, grade III or IV encephalopathy [5], hepatocellular carcinoma; 3) no history of alcoholism; 4) no parenchymal lung involvement or pleural effusion on routine chest radiographic image; and 5) absence of diagnostic criteria for asthma, chronic bronchitis or emphysema according to the American Thoracic Society [6]. The anthropometric and clinical data of the patients are presented in table 1 . Two patients were nonsmokers, and the remaining six former smokers. Cirrhosis had been diagnosed by history, clinical examination, laboratory findings and, when not contra-indicated, liver biopsy. Viral hepatitis was the cause of cirrhosis in seven patients, and cryptogenic cirrhosis was diagnosed in one patient. From a clinical point of view, the patients' conditions varied from moderate to severe according to the Child-Pugh classification [7]. None of the patients complained of dyspnoea.

After admission to hospital, patients were given a diet containing $40 \mathrm{mEq} \cdot \mathrm{day}^{-1}$ of sodium, with a controlled fluid intake $\left(\leq 1 \mathrm{~L} \cdot \mathrm{day}^{-1}\right)$. In patients with hyponatraemia (serum sodium $<130 \mathrm{mEq} \cdot \mathrm{L}^{-1}$ ) water ingestion was restricted to $500 \mathrm{~mL} \cdot$ day $^{-1}$.

The protocol of the study was approved by the University's Ethics Committee and written informed consent was obtained from each subject.

\section{Protocol}

The study was conducted on three consecutive days. On the first day, blood gas values, lung volumes, and inspiratory muscle strength were measured, while the patients were seated in a comfortable high-backed armchair; they were then placed in a comfortable supine position and breathed quietly through the pneumotachograph. After a 10 min period of acclimatization, breathing pattern variables, rib cage and abdominal volume displacements, and pleural and gastric pressure swings were recorded during tidal breathing. On the second day, large volume paracentesis (LVP) was performed. LVP was defined as removal of $>2,000 \mathrm{~mL}$ of ascitic fluid at a single tap. The amount of fluid removed with paracentesis was variable, but always $>3.5 \mathrm{~L}$. Paracentesis was performed via gravity with a No. 16 gauge catheter, under local anaesthesia, in the left lower abdominal quadrant over a $5 \mathrm{~h}$ period, using standard aseptic technique. Patients were initially in the supine position; they were turned into a lateral position if necessary. Ultrasound was performed to define the best position for the patient, in order to remove the largest quantity of ascites.
After tap, patients reclined for $2 \mathrm{~h}$ on the opposite side to prevent leakage of ascitic fluid. Samples of ascitic fluid were taken during each paracentesis for total and differential white blood cell counts, cytology, biochemical examination and cultures. During each paracentesis, human albumin (human albumin 20\%; Immuno AG, Austria) was administered intravenously at a dosage of $10 \mathrm{~g}$ per litre of ascitic fluid removed [8]. On the third day, pulmonary function testing was repeated using the same methods as employed on the first day. On the second and third day, blood electrolytes and body weight were recorded.

\section{Measurements}

Routine spirometry was performed using a watersealed spirometer (Pulmonart Godart; Sensormedics Corp., Yorba Linda, CA, USA). Functional residual capacity (FRC) was measured by the helium dilution technique. The normal values for lung volumes were those of the European Coal and Steel Community [9]. Arterial blood samples were taken while the subjects were breathing room air, and blood gas values were analysed (ABL-3 analyzer; Radiometer, Copenhagen, Denmark).

For ventilation measurements, patients breathed through a Fleisch No. 3 pneumotachograph connected to a differential pressure transducer. Volume was obtained by electrical integration of the flow signal. From the spirogram the following parameters were derived: inspiratory time $(t \mathrm{I})$, expiratory time $(t \mathrm{E})$, total time of the respiratory cycle (ttot) and tidal volume $(V \mathrm{~T})$. Respiratory frequency $(f \mathrm{R}=1 /$ tot $\times 60)$ and minute ventilation $\left(V^{\prime} \mathrm{E}=V \mathrm{~T}\right.$ $\times f \mathrm{R})$ were also calculated. End-tidal carbon dioxide tension $\left(P \mathrm{ET}, \mathrm{CO}_{2}\right)$ and arterial oxygen saturation $\left(\mathrm{Sa}, \mathrm{O}_{2}\right)$ were monitored continuously by an infra-red $\mathrm{CO}_{2}$ meter (Datex Normocap, Helsinki, Finland) and an ear oximeter (Radiometer, Copenhagen, Denmark), respectively. Mouth pressure during tidal breathing was measured using a pressure transducer (Statham P23ID; Statham Lab. Inc., Hato Rey, Puerto Rico).

Changes in thoracoabdominal dimensions were determined in 6 of the 8 patients by linearized magnetometers. Pairs of magnetometer coils were attached on the midline to measure the anteroposterior diameters of the lower rib cage at the level of the nipples (fifth costal cartilage) and of the abdomen approximately $2 \mathrm{~cm}$ above the umbilicus. The magnetometer output voltages were displayed on an x-y Tektronics 5115 storage oscilloscope (Tektronics Corp., Beaverton, OR, USA), and photographed using a Polaroid camera (Polaroid Corp., 
Cambridge, MA, USA). Signal gains were adjusted so that isovolume manoeuvres ("belly-in") produced a slope of approximately -1 when the anteroposterior diameter of the abdomen was plotted against the anteroposterior diameter of the lower rib cage [10].

Oesophageal pressure $(P$ oes $)$ was measured with a conventional balloon-tipped catheter system [11] connected to a differential pressure transducer (Validyne, Northridge, CA, USA), as described previously [12]. The balloon was positioned in the mid-oesophagus and contained 0.4 $\mathrm{mL}$ of air. Oesophageal pressure was used as an index of pleural pressure $(P \mathrm{pl})$. Gastric pressure $(P \mathrm{ga})$ was simultaneously measured with a similar balloon-tipped catheter system connected to a second differential pressure transducer. This balloon was positioned in the stomach with the tip 65-70 $\mathrm{cm}$ from the nares, and contained $2 \mathrm{~mL}$ of air. Transdiaphragmatic pressure $(P \mathrm{di})$ was obtained by subtracting $P$ pl to $P$ ga.

Inspiratory muscle strength was assessed by measuring minimal (i.e. the greatest negative) inspiratory pleural pressure $(P$ pl,min $)$ and maximal transdiaphragmatic pressure $(P$ di,max $)$ at FRC during sniff manoeuvres [13]. The patients were repeatedly encouraged to try as hard as possible, and they had a visual feedback of the pressure generated. The manoeuvres were repeated until three measurements with less than $5 \%$ variability were recorded. The lowest $P$ pl,min and the highest $P$ di,max values obtained were used for analysis and compared with those of age-matched normal subjects: the lower limit of normality was calculated as the mean value $-\mathrm{SD} \times 1.65$.

$P$ pl and $P$ ga were also recorded during tidal breathing: $P \mathrm{pl}(P \mathrm{pl}, \mathrm{sw})$ and $P$ ga $(P \mathrm{ga}, \mathrm{sw})$ swings were calculated as the difference between the pressure measured at end-expiration and the peak value measured during inspiration. These values were compared with those of age-matched normal subjects: the upper limit of normality was calculated as the mean value $+\mathrm{SD} \times 1.65$. Total lung resistance $(R \mathrm{~L})$ and lung dynamic elastance $(E 1$,dyn $)$ were measured during breathing at rest. Total lung resistance was obtained using the isovolume method of FRANK et al. [14]. Dynamic lung elastance was determined by dividing the difference in $P$ pl between points of zero flow by $V \mathrm{~T}$. To evaluate end-expiratory alveolar pressure, we used the indirect method recently described by HaluszKa et al. [15] and Dal VECCHIO et al. [16], rather than the direct method of airway occlusion. This was because awake subjects react to airway oc- clusion in an unpredictable fashion, so that no reliable measurements of alveolar pressure can be obtained. We thus looked for the presence of a time lag between the fall in $P$ pl at the onset of the inspiratory effort and the onset of inspiratory airflow, and measured the negative deflection in $P \mathrm{pl}$ that preceded the start of inspiratory flow (fig. 1). This negative deflection in $P$ pl will be referred to as intrinsic positive end-expiratory pressure (PEEPi) for consistency with previous investigations [15, $16]$.

The change in $P$ ga resulting from the contraction of the abdominal muscles during expiration was also assessed. In agreement with NINANE et al. [17], the increase in $P$ ga during the expiratory phase of the breathing cycle was taken as a reflection of the mechanical effect of abdominal muscle contraction. The ratio of pleural pressure swing to tidal volume $(P \mathrm{pl}, \mathrm{sw} / V \mathrm{~T})$ was also calculated, in order to assess the pressure necessary to produce tidal volume.

All signals were recorded continuously on a multichannel chart recorder (TA4000; Gould, Valley View, $\mathrm{OH}, \mathrm{USA})$.

\section{Statistical analysis}

Mean values and standard deviations of the mean were calculated for all variables. Data obtained under control conditions and after LVP were compared by Wilcoxon test for paired samples. Single and stepwise multiple regression analyses were performed to assess the relationships between variables. The proportion of total variance of the dependent variable accounted for by the predictor variable(s) is reported as the square of correlation coefficient $\left(\mathrm{r}^{2}\right)$, expressed as a percentage. Single regression analysis was carried out by least square method. All statistical analyses were carried out using the SPSS for Windows 6.0 package (SPSS Inc., Chicago, IL, USA).

\section{Results}

In all patients, the decrease in body weight from the second to the third day was equal to or greater than the weight of fluid removed; moreover, there was a close relationship between the amount of fluid removed and the decrease in body weight $(r=0.96 ; p<0.0002)$. Blood electrolytes did not significantly change after LVP. a)

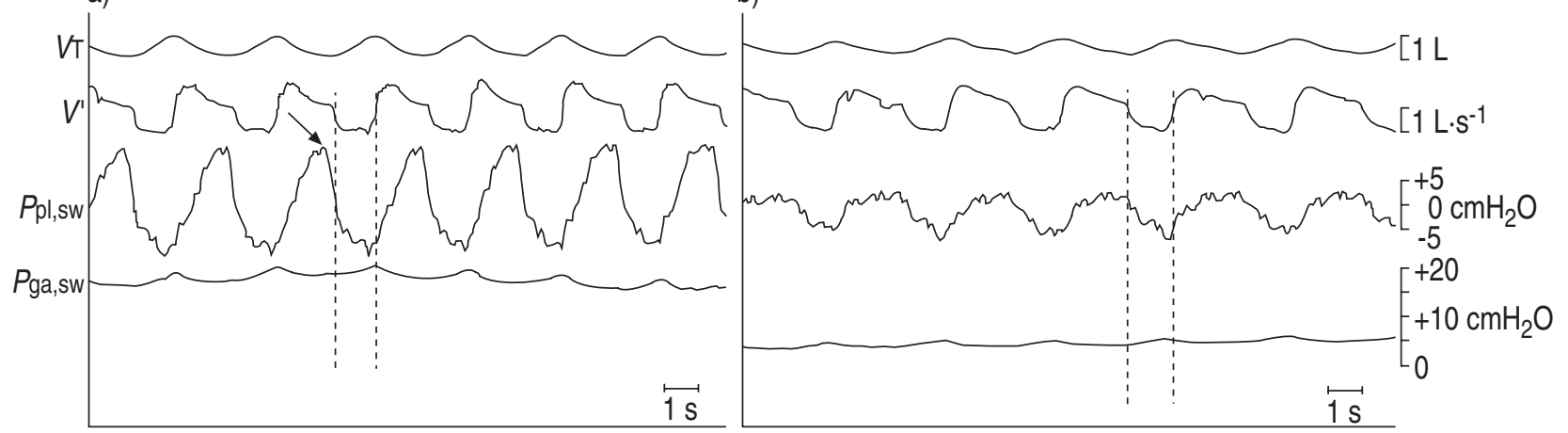

Fig. 1. - Recordings in a representative patient: a) before; and; b) after large volume paracentesis (LVP). Arrow indicates the beginning of $P$ pl decrease. $V$ T: tidal volume; $V^{\prime}$ : respiratory flow; $P$ pl,sw: pleural pressure swings; $P$ ga,sw: gastric pressure swings. Dashed vertical lines indicate the beginning of inspiratory and expiratory flow, from left to right, respectively. 
Table 2. - Pulmonary function data, arterial blood gas values and mechanical lung characteristics in the patients with cirrhotic ascites

\begin{tabular}{|c|c|c|c|}
\hline Parameter & Before LVP & After LVP & p-value \\
\hline VC \% pred & $90 \pm 10$ & $98 \pm 17$ & NS \\
\hline FRC \% pred & $86 \pm 19$ & $98 \pm 14$ & $<0.014$ \\
\hline TLC $\%$ pred & $94 \pm 10$ & $97 \pm 11$ & NS \\
\hline RV \% pred & $107 \pm 21$ & $103 \pm 24$ & NS \\
\hline FEV1 \% pred & $87 \pm 12$ & $100 \pm 17$ & $<0.009$ \\
\hline FEV1/VC \% & $74 \pm 7$ & $79 \pm 5$ & NS \\
\hline IC L & $2.9 \pm 0.63$ & $2.7 \pm 0.53$ & $<0.029$ \\
\hline ERV L & $0.58 \pm 0.30$ & $0.98 \pm 0.45$ & $<0.014$ \\
\hline$P \mathrm{a}, \mathrm{O}_{2} \quad \mathrm{mmHg}$ & $11.96 \pm 1.03$ & $12.12 \pm 0.64$ & NS \\
\hline $\mathrm{Pa}_{\mathrm{a}, \mathrm{CO}_{2}} \mathrm{mmHg}$ & $4.37 \pm 0.43$ & $4.52 \pm 0.36$ & NS \\
\hline $\mathrm{pH}$ & $7.44 \pm 0.02$ & $7.44 \pm 0.02$ & NS \\
\hline$R \mathrm{~L} \mathrm{cmH}_{2} \mathrm{O} \cdot \mathrm{L}^{-1} \cdot \mathrm{s}$ & $5.9 \pm 1.6$ & $5.0 \pm 1.5$ & NS \\
\hline$E 1$, dyn $\mathrm{cmH}_{2} \mathrm{O} \cdot \mathrm{L}^{-1}$ & $11.4 \pm 2.6$ & $10.0 \pm 2.0$ & $<0.01$ \\
\hline PEEPi $\mathrm{cm}_{2} \mathrm{O}$ & $4.3 \pm 3.5$ & $1.1 \pm 1.3$ & $<0.02$ \\
\hline
\end{tabular}

Values are presented as mean \pm SD. VC: vital capacity; FRC: functional residual capacity; TLC: total lung capacity; RV: residual volume; FEV1: forced expiratory volume in one second; IC: inspiratory capacity; ERV: expiratory reserve volume; $\mathrm{Pa}_{\mathrm{a}} \mathrm{O}_{2}$ : arterial partial tension of oxygen; $\mathrm{Pa}_{\mathrm{a}, \mathrm{CO}_{2}}$ : arterial partial tension of carbon dioxide; $R \mathrm{~L}$ : total lung resistance; $E \mathrm{l}$,dyn: dynamic elastance of the lung; PEEPi: positive end-expiratory alveolar pressure; $\%$ pred: percentage of predicted value; LVP: large volume paracentesis; Ns: nonsignificant. $(1 \mathrm{mmHg}=0.133$ $\mathrm{kPa})$.

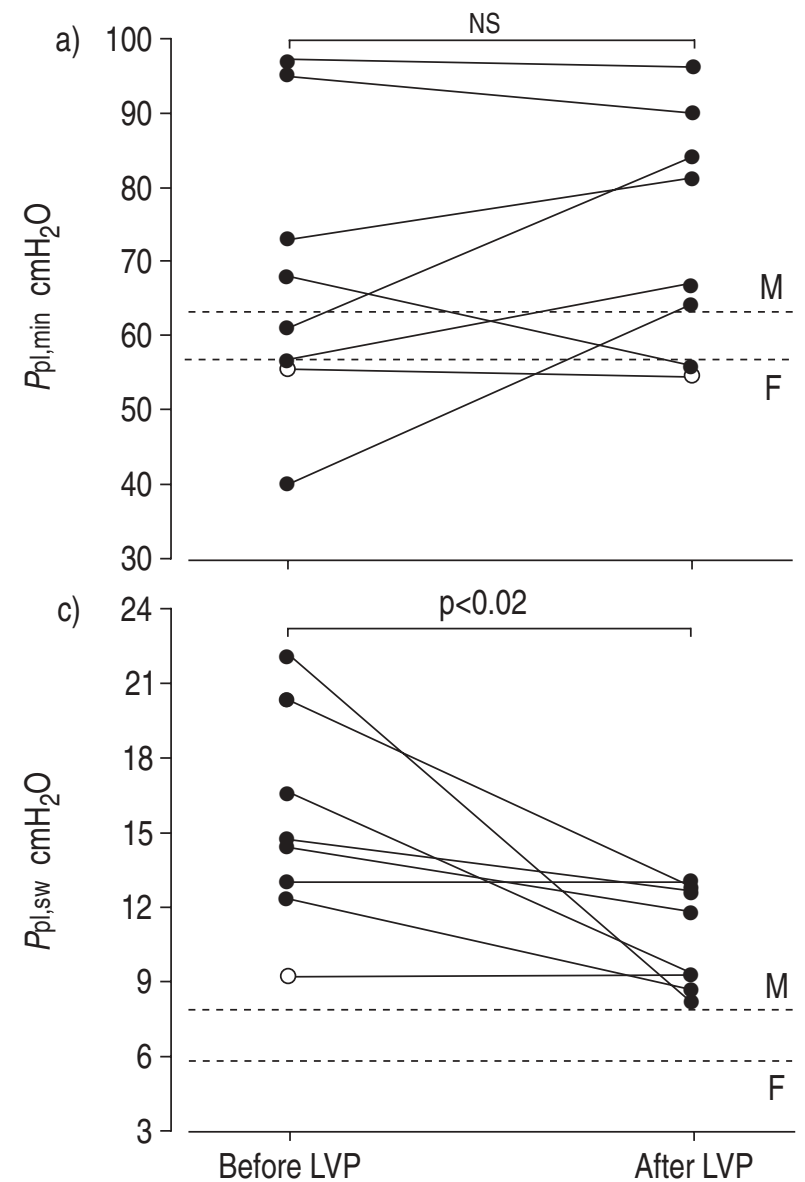

\section{Lung volumes}

Pulmonary function data before and after LVP are presented in table 2. Before LVP, vital capacity (VC), FRC, and forced expiratory volume in one second (FEV1) varied from normal to moderately reduced; total lung capacity (TLC) and residual volume (RV) were normal in all but one subject, while FEV1/VC was slightly reduced in three subjects. Expiratory reserve volume (ERV) was markedly reduced in four subjects and slightly reduced in three. After LVP, the FRC, FEV1 and ERV increased significantly, while inspiratory capacity (IC) decreased significantly; VC also increased but the change did not reach the level of significance, while TLC, RV and $\mathrm{FEV} 1 / \mathrm{VC}$ remained largely unchanged.

\section{Breathing pattern and blood gas values}

Before LVP, $V^{\prime}$ E was elevated $\left(14.4 \pm 2.4 \mathrm{~L} \cdot \mathrm{min}^{-1}\right)$, due to large tidal volume $(0.82 \pm 0.23 \mathrm{~L})$ and high respiratory frequency $\left(18.5 \pm 4.3\right.$ breaths $\left.\cdot \mathrm{min}^{-1}\right)$. No changes were observed after $\operatorname{LVP}\left(V^{\prime} \mathrm{E}=13.7 \pm 1.8 ; V \mathrm{~T}=0.81 \pm 0.25 \mathrm{~L}\right.$; $f \mathrm{R}=17.8 \pm 3.8$ breaths $\left.\cdot \mathrm{min}^{-1}\right)$. Mean $\mathrm{pH}$ was within normal limits, arterial oxygen tension $\left(\mathrm{Pa}_{\mathrm{a}} \mathrm{O}_{2}\right)$ was only slightly reduced and arterial carbon dioxide tension $\left(P \mathrm{a}, \mathrm{CO}_{2}\right)$ was low; LVP did not cause significant changes (table 2).

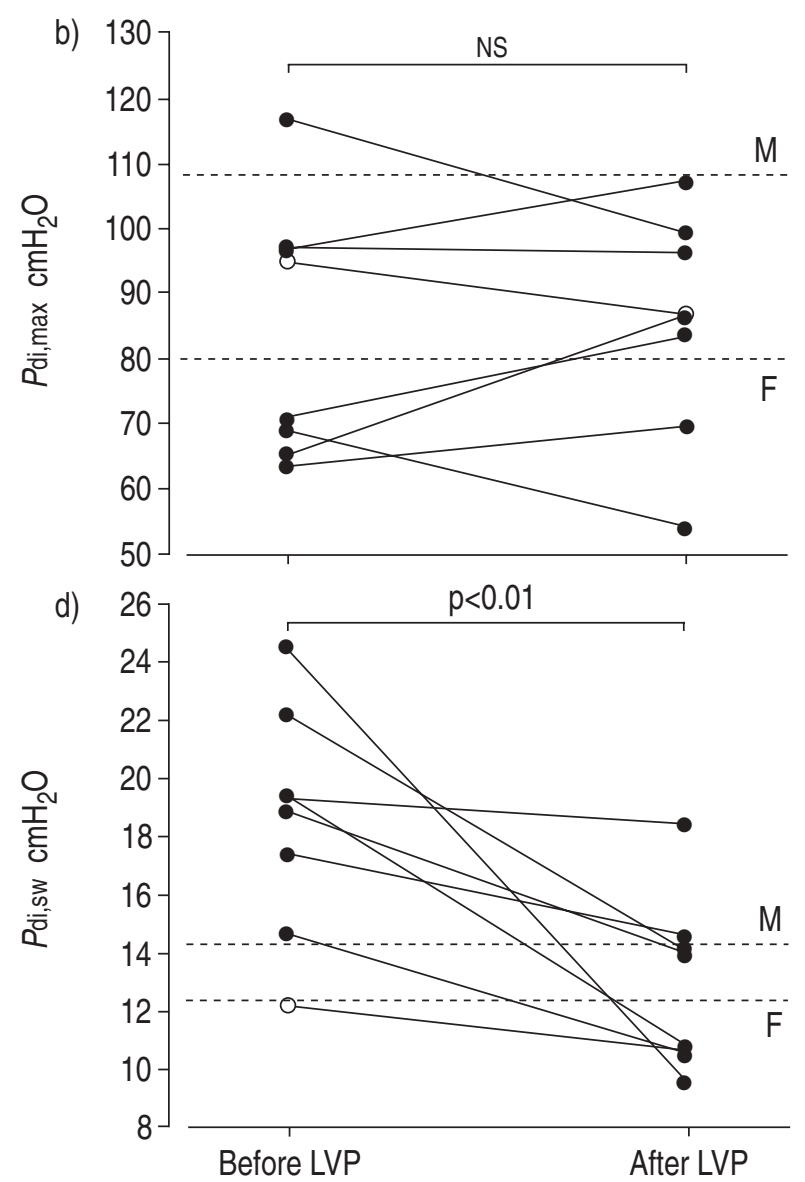

Fig. 2. - a) Minimal pleural pressure $(P$ pl,min); b) maximal transdiaphragmatic pressure $(P$ di,max $)$; c) pleural pressure swings $(P$ pl,sw); and d) transdiaphragmatic pressure swings $(P \mathrm{di}, \mathrm{sw})$ before and after large volume paracentesis (LVP). Dashed lines represent the lower limits of the normal range (mean $-1.65 \mathrm{SD}$ ) for males $(\mathrm{M})$ and females $(\mathrm{F})$, respectively. $\bullet$ : male; O: female; NS: nonsignificant. 


\section{Inspiratory muscle strength}

The mean inspiratory muscle strength in the sitting position was not significantly different from that of normal subjects. However, looking at individual values, before LVP, $P$ pl,min was normal in four patients, just below the lower normal limit in two, and low in the remaining two (fig. 2a), whereas $P$ di,max was low in six patients and normal in two (fig. 2b). After LVP, neither $P$ pl,min nor $P$ di,max changed consistently (fig. $2 \mathrm{a}$ and $\mathrm{b}$ ).

\section{Chest wall mechanics}

Compared to the normal range of our laboratory, swings of pleural pressure $(P \mathrm{pl}, \mathrm{sw})$ (figs. $2 \mathrm{c}$ and 3$)$ and transdiaphragmatic pressure $\left(P_{\mathrm{di}, \mathrm{sw}}\right)$ (figs. $2 \mathrm{~d}$ and 3 ) during tidal breathing in the supine position were large before LVP and fell significantly thereafter. The gastric pressure swing $(P$ ga,sw $)$ also decreased significantly with LVP (from 3.2 to $2.1 \mathrm{cmH}_{2} \mathrm{O} ; \mathrm{p}<0.01$ ). Plots of $P \mathrm{pl}$ versus $P$ ga before and after LVP are illustrated in figure 3. It appears that with LVP: 1) both end-expiratory pleural pressure $(P \mathrm{pl}, \mathrm{EE})$ and end-expiratory gastric pressure $(P$ ga,EE) decreased significantly $(\mathrm{p}<0.02$ for both); and 2$)$ end-inspiratory pleural pressure $(P$ pl,EI $)$ did not change, whilst end-inspiratory gastric pressure $(P$ ga,EI $)$ decreased markedly $(\mathrm{p}<0.01)$.

The magnetometry data show that during quiet breathing in supine position the rib cage contributed $0.18 \mathrm{~L}$ and abdomen $0.72 \mathrm{~L}$ ( 21 and $79 \%$, respectively) to tidal volume and these contributions did not change significantly after LVP (rib cage $0.21 \mathrm{~L}$ and abdomen $0.64 \mathrm{~L}$ (27 and 73\%, respectively)) (fig. 4a). The ratio of abdominal displacement $(V \mathrm{ab})$ to $P$ ga,sw $\left(V \mathrm{ab} / P_{\mathrm{ga}, \mathrm{sw}}\right)$ during quiet breathing was not significantly modified by LVP (0.238 and $0.295 \mathrm{~L} \cdot \mathrm{cmH}_{2} \mathrm{O}^{-1}$ before and after LVP, respectively). In four patients, the changes $V \mathrm{ab} / P$ ga,sw were minor, whilst in the other two patients $V$ ab $/ P$ ga,sw increased markedly. Plots of $V$ ab/Pga,sw in a representative subject before and after LVP are presented in figure $4 \mathrm{~b}$.

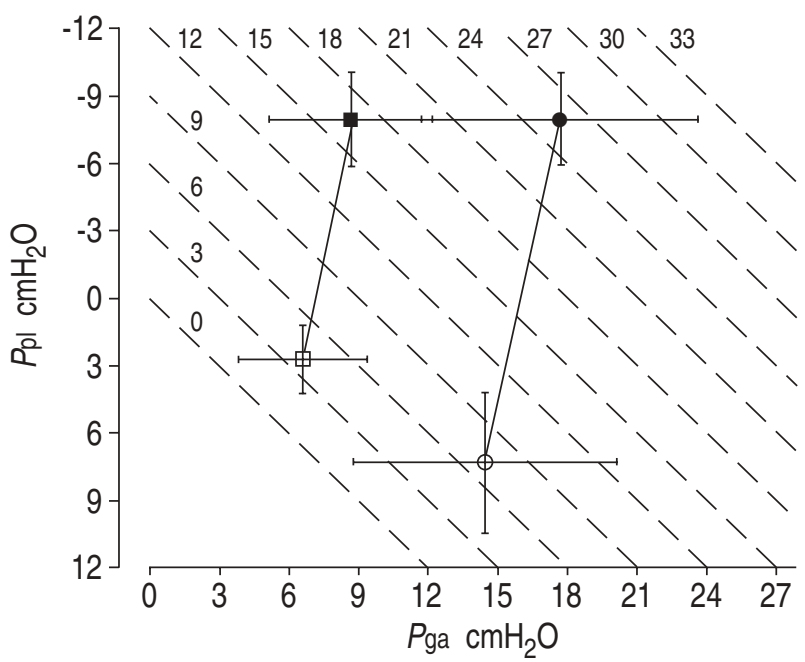

Fig. 3. - Plot of gastric pressure $(P$ ga $)$ versus pleural pressure $(P \mathrm{pl})$ at end-expiration (open symbols) and at end-inspiration (closed symbols) before (circles) and after (squares) large volume paracentesis (LVP). Dashed lines join points with the same $P$ di (iso $P$ di). The value of each iso $P$ di line is indicated.
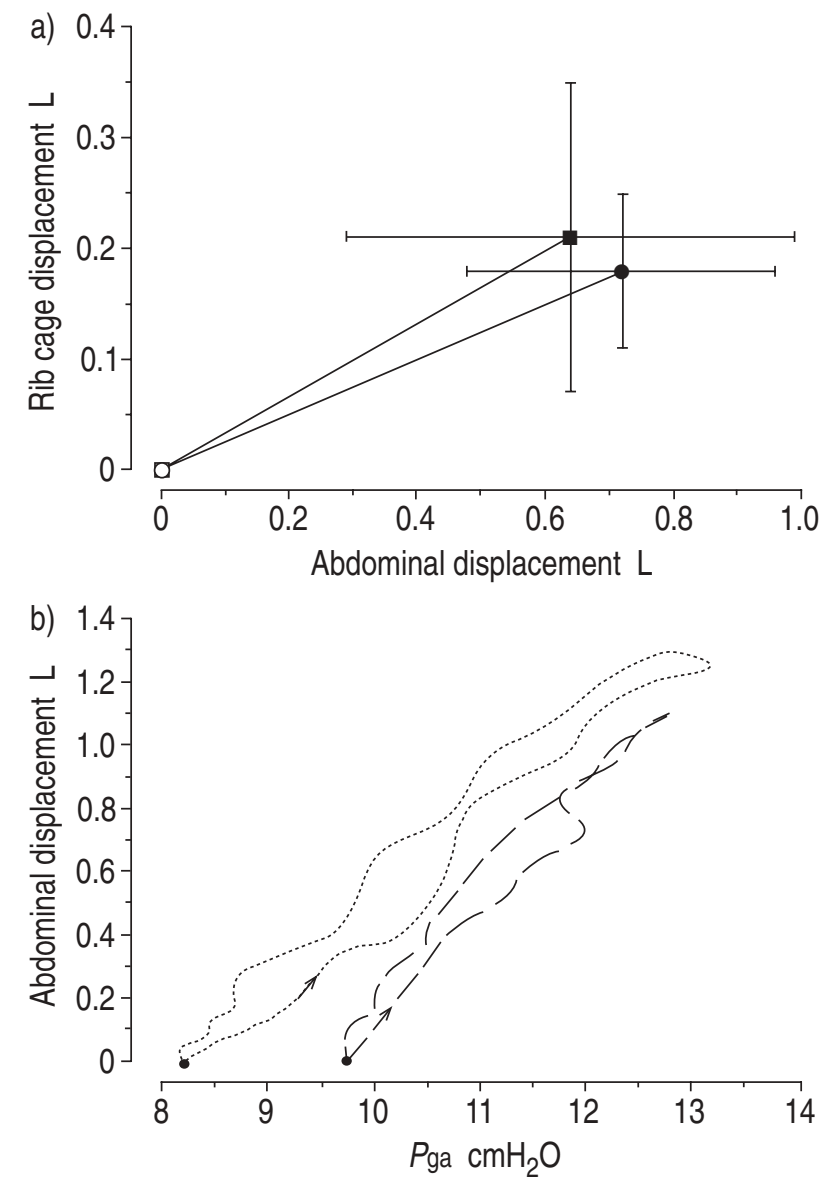

Fig. 4. - a) Plots of rib cage displacement versus abdominal displacement during quiet breathing at end-expiration (open symbols) and end-inspiration (closed symbols) before (circles) and after (squares) large volume paracentesis (LVP). Values are presented as mean \pm SD. b) Plots of abdominal displacement versus gastric pressure (Pga) in one representative subject before (dashed line) and after (dotted line) LVP. In each plot, closed circle indicates end-expiration, and the arrow marks the inspiratory phase of the breathing cycle and indicates the direction of the loop. In both panels, end-expiratory lung volume before and after LVP was arbitrarily set to zero.

\section{Lung mechanics}

In the supine position, $R \mathrm{~L}$ was slightly increased [9], E1,dyn was high in all subjects and PEEPi was present in 7 out of 8 patients. After LVP, RL did not change significantly, whereas both E1,dyn and PEEPi decreased significantly (table 2 and fig. 1).

\section{Interrelated measurements}

Changes in $P$ pl,EE, $P$ pl,sw and PEEPi were closely related to the amount of fluid removed (fig. 5a-c). Moreover, changes in PEEPi with LVP were significantly related to changes in $P$ pl,EE (fig. 6). Changes in $P \mathrm{pl}, \mathrm{sw} / V \mathrm{~T}$ induced by LVP were closely related to changes in $E 1$,dyn and PEEPi $(r=0.83 ; p<0.02$; and $r=0.91 ; p<0.002$, respectively). Stepwise multiple regression analysis (table 3 ) showed that changes in $E 1$,dyn $(\mathrm{F}=7.32 ; \mathrm{p}=0.042)$ and PEEPi $(\mathrm{F}=18.14 ; \mathrm{p}<0.008)$ induced by LVP explained $90 \%$ of the variability of changes in $P$ pl,sw $/ V$ T. There were no significant relationships between PEEPi and FEV1, FEV1/FVC, or breathing pattern. 

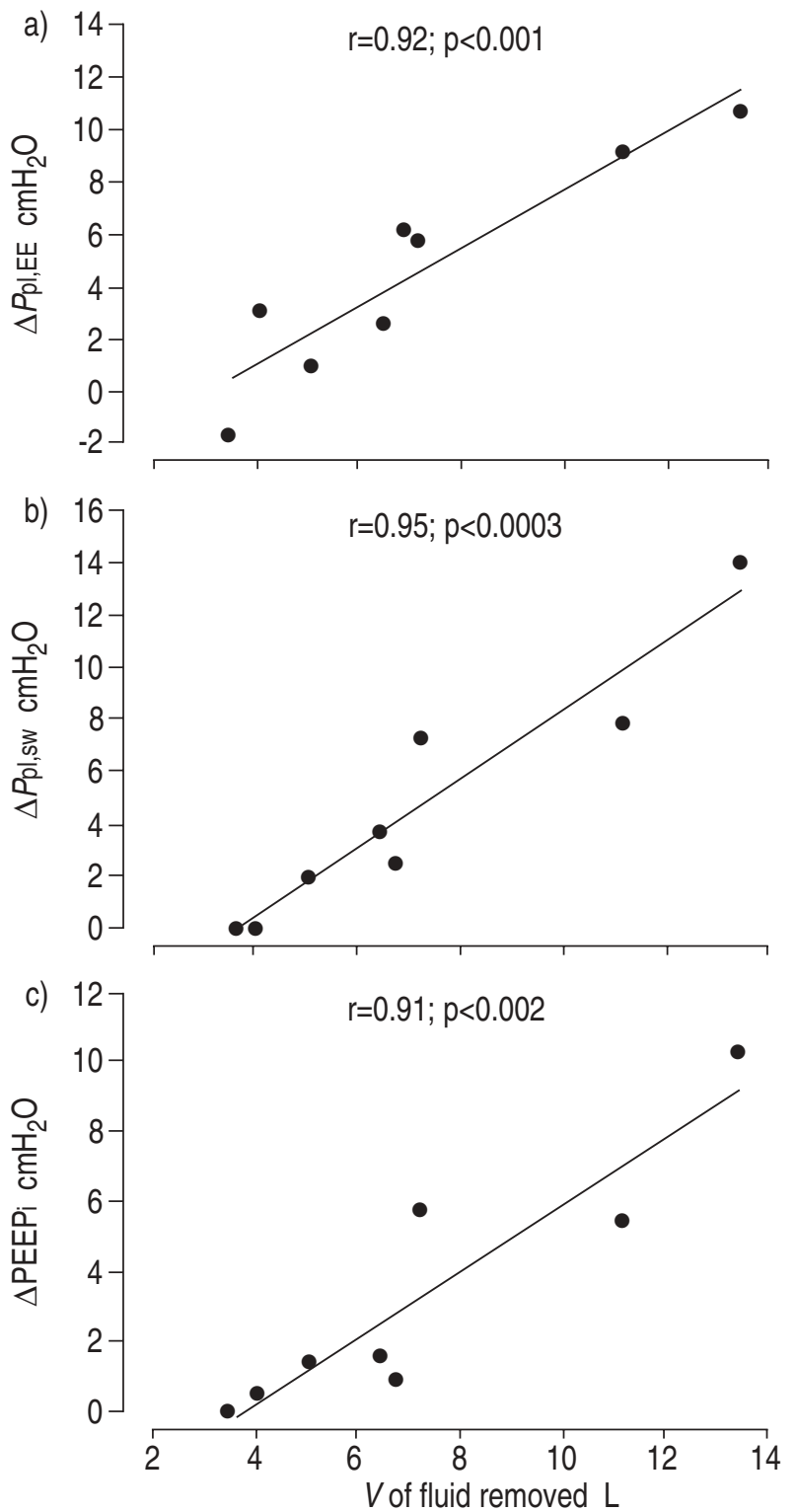

Fig. 5. - Relationship of volume $(V)$ of fluid removed versus changes $(\Delta)$ in: a) end-expiratory pleural pressure $(P \mathrm{pl}, \mathrm{EE})$; b) tidal swings of pleural pressure $(P \mathrm{pl}, \mathrm{sw})$; and c) positive end-expiratory alveolar pressure $(\mathrm{PEEP})$, respectively.

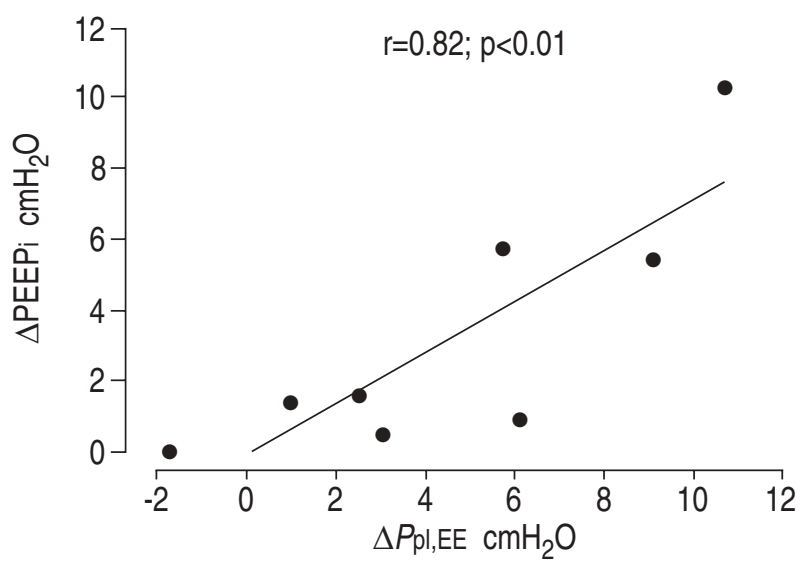

Fig. 6. - Relationship of changes in PEEPi versus changes in $P$ pl,EE.
Table 3. - Stepwise multiple regression for changes $(\Delta)$ in $P$ pl,sw/VT induced by LVP

\begin{tabular}{lccc}
\hline Variable & Coefficient & model $\mathrm{r}^{2} \%$ & $\mathrm{p}$-value \\
\hline Constant & -1.78 & & \\
$\Delta \mathrm{PEEPi}$ & 1.087 & 80.5 & 0.008 \\
$\Delta E \mathrm{I}$,dyn & 3.21 & 90.5 & 0.042 \\
\hline
\end{tabular}

$P$ pl,sw: pleural pressure swings; $V$ T: tidal volume; LVP: large volume paracentesis; PEEPi: positive end-expiratory alveolar pressure; E1,dyn: dynamic elastance of the lung.

\section{Discussion}

The main findings of the present study can be summarized as follows. Firstly, inspiratory muscle strength, measured in a sitting position, was normal or reduced and was not modified by LVP. Secondly in the supine position, pleural and transdiaphragmatic pressure swings during tidal breathing were large and decreased with LVP; the lung elastic load was increased and a threshold load was present in most patients; both elastic and threshold load decreased with LVP.

A limitation of this study is represented by the fact that no ultrasound examination was performed on the third day in order to exclude the possibility that ascites developed after LVP. However, the following points should be considered: 1) the decrease in body weight was equal to or greater than the weight of fluid removed in all patients, and there was a close relationship between the two; and 2) during paracentesis, patients were given large amounts of human albumin (see Methods), which has been shown [18] to prevent the occurrence of hypovolaemia and, therefore, rapid reaccumulation of ascites. We are confident that significant fluid accumulation in the abdomen was unlikely to occur in the time interval between paracentesis and measurements.

\section{Pulmonary volumes}

A redistribution of lung volumes occurred: IC increased, whereas ERV and FRC decreased. In conditions such as ascites or pregnancy, the decrease in FRC is thought to be determined by an increased intra-abdominal pressure, which elevates the diaphragm in the thorax $[1,19]$. Consistent with this hypothesis are the observations [1-3] that after LVP the FRC and ERV increase, which is confirmed by the present study.

\section{Breathing pattern and arterial blood gas values}

Chronic hyperventilation with a resulting compensated respiratory alkalosis is a common observation in patients with cirrhosis [20-22]. The present data confirm this observation, the increase in $V^{\prime} \mathrm{E}$ being due to an increase both of tidal volume and respiratory frequency. Several mechanisms have been proposed to explain hyperventilation in cirrhotic patients $[20,21]$, but the real reason is still obscure. No change in $V^{\prime} \mathrm{E}$ was observed after LVP, and this suggests that ascites was probably not implicated in this abnormality. Hypoxaemia is also frequently associated with cirrhosis and different mechanisms have been thought to be involved in 
determining it: ventilation/perfusion $\left(V^{\prime} \mathrm{A} / Q^{\prime}\right)$ mismatching; intrapulmonary shunt; limitation of oxygen diffusion; and inadequate vascular tone $[22,23]$. Two patients exhibited mild hypoxaemia (Nos. 4 and 8), but on average $\mathrm{Pa}, \mathrm{O}_{2}$ was normal and unchanged after LVP.

\section{Inspiratory muscle strength}

The patients studied showed normal or decreased inspiratory muscle strength, which did not change with LVP. These findings are consistent with those of HouRANI et al. [24], who measured respiratory muscle strength in 116 patients with severe liver disease of varying aetiology and found a decreased maximal inspiratory pressure (MIP) in $56 \%$ of them. The reasons as to why inspiratory muscle strength may be decreased in cirrhotic ascitic patients are not clear. In fact, the effects of increased abdominal pressure on diaphragmatic strength are controversial. In patients undergoing continuous ambulatory peritoneal dialysis (CAPD), a situation that from a mechanical point of view is similar to ascites, PREZANT et al. [25] reported that an increase of peritoneum dialysate from 0 to $3 \mathrm{~L}$ induced progressive decrease of FRC and increase both of MIP and $P \mathrm{di}$, measured in sitting position. Two factors have been thought to be involved in determining the increase in diaphragmatic strength in patients with raised intra-abdominal pressure $[25,26]: 1)$ the elevation of the diaphragm in the thorax by the high intra-abdominal pressure could lengthen diaphragmatic fibres, increasing the area of apposition of the diaphragm to the rib cage and improving the length-tension relationship of the diaphragm; and 2) the presence of liquid in the abdomen could decrease the abdominal compliance, thus providing a more effective fulcrum for the diaphragmatic action.

Based on the above considerations, one could expect that diaphragmatic strength is increased in ascitic patients and decreases with LVP. However, in the patients studied, LVP induced inconsistent changes. At variance with PrEZANT et al. [25], SiafaKas et al. [27] found that MIP, measured in sitting position, was low during CAPD and increased after drainage of the fluid. There are several reasons that could explain these discrepancies. Firstly, the positive effect of diaphragmatic elevation may be counterbalanced by an enlargement of the lower rib cage, leading to a greater radius of curvature of the diaphragm and to a reduction of the area of apposition, as suggested for pregnant women [26, 28]; moreover, an excessive amount of fluid in the abdomen could displace the diaphragm far beyond its optimal length, thus reducing its strength. Secondly, the increase in abdominal compliance and the consequent fulcrum effect may not be so important, as suggested by the lack of modifications in $V \mathrm{ab} / P$ ga,sw with LVP. Thirdly, consistent with the results of ZocCHI et al. [29], the presence of liquid in the abdomen can alter the actions of diaphragm changing the linkage between its costal and crural parts. The forces generated by the costal and crural parts of the diaphragm are additive if these parts are mechanically arranged in parallel, but not if they are mechanically arranged in series. In the latter case, the ability of diaphragm to generate force would be reduced. In conclusion, the net effect of increased abdominal pressure on inspiratory muscle force probably depends on the balance between the above-mentioned factors, and this may explain the different results observed in the present study and in other studies [25, 27].

The lack of effects of LVP on inspiratory muscle strength suggests that other mechanisms linked to liver disease are probably involved in determining inspiratory muscle weakness. In this context, the metabolic alterations characteristic of liver cirrhosis (such as hypoproteinaemia and electrolyte abnormalities) might play a role, as confirmed by the observation of muscle wasting in patients with liver diseases [24], and, in particular, in cirrhotic patients [30]. Finally, one has also to consider that $P$ di,max is an effort-dependent manoeuvre, so that variations in effort pre- and postparacentesis might influence the measure. Due to the clinical condition of our patients, we could not perform phrenic nerve stimulation, which is the only way to obtain more reliable measures of diaphragmatic strength.

\section{Chest wall mechanics}

Our patients showed high $P \mathrm{pl}, \mathrm{sw}$ and relatively low $P$ ga,sw, both of which decreased significantly with LVP. Figure 3 shows that an end-inspiration, pleural pressure was normal or only slightly altered, while at end-expiration it was markedly increased. This increase appears to be the consequence of the high intra-abdominal pressure, as clearly indicated by the close relationship between the amount of fluid removed and decrease both in $P$ pl,EE and $P$ pl,sw (fig. $5 \mathrm{a}$ and b). Swings of $P$ di were also high, indicating an increased activation of inspiratory muscles, and decreased significantly with LVP (figs. $2 \mathrm{~d}$ and 3 ), this reduction being mainly due to a decreased $P$ di,EI (fig. 3). Consistent with the observation of a significant reduction both in lung elastic load and threshold load after paracentesis, a decrease in overloading and, thereby, a reduced activation of inspiratory muscles are likely explanations for the decrease of $P_{\mathrm{di}, \mathrm{EI}}$ and $P$ di,sw after LVP. The absence of significant modifications in $V \mathrm{ab} / \mathrm{Pga}$ and previous observations in experimental animals [29] argue against the possibility that liquid subtraction induced an increase of abdominal compliance, causing a lesser impediment to inspiratory diaphragmatic descent and, thus, resulting in a greater diaphragmatic shortening and the development of a lower $P$ di,EI and $P$ di,sw. Finally, the finding of a high $P$ di,sw accompanied both by high $P$ pl,sw and low $P$ ga,sw suggests an important contribution of the rib cage inspiratory muscles to generation of inspiratory pressure.

The magnetometry data show that the generation of tidal volume was contributed mainly by the abdomen and the relative contributions of abdomen and rib cage did not change with LVP. This is consistent with the findings of HANSON et al. [4], who observed in ascitic patients a relationship between lung volumes and intraabdominal pressure, but, surprisingly, no change in intraabdominal pressure with paracentesis. The explanation for this finding was that in ascitic patients abdominal muscles within the chronically distended abdominal wall are stretched beyond their elastic limit and are, thus, overly compliant [4]. Consistent with this hypothesis, the observation that a low $P$ ga,sw was accompanied 
by a high abdominal contribution to tidal volume generation confirms that abdominal compliance is probably very high in these patients. Finally, the lack of changes both in the contribution of the abdomen to the generation of tidal breathing and in the $V \mathrm{ab} / P$ ga with LVP argues against change in abdominal compliance with LVP, and supports the hypothesis of HANSON et al. [4].

\section{Lung mechanics}

Another important finding of this study is the elevated load on the inspiratory muscles due both to an increased pulmonary dynamic elastic load $(E 1$, dyn $)$ and the presence of a threshold load (PEEPi). In order to overcome the increased lung mechanical load, ascitic patients have to increase the $P \mathrm{pl}, \mathrm{sw}$ at each breath (table 3 ). The interrelationships between changes in $P$ pl,sw $/ V \mathrm{~T}$ and changes in El,dyn and PEEPi indicate that after paracentesis the load on the inspiratory muscles decreased and that a lower $P \mathrm{pl}$ was necessary to generate the same $V \mathrm{~T}$. The following two factors are likely to contribute to the increased E1,dyn in cirrhotic patients. Firstly, closure of alveolar units; this mechanism is thought to be involved in causing a decrease in lung compliance both in obese patients $[31,32]$, and in normal subjects during chest wall strapping $[33,34]$. The closure of airways in cirrhotic patients may be a consequence of the high intra-abdominal pressure and the consequent increased pleural pressure (see below). Secondly, increase in lung elastic recoil due to interstitial pulmonary oedema, which is thought to be present in patients with liver cirrhosis [35].

An interesting finding was the presence of a PEEPi. Although the reasons for the presence of a PEEPi in cirrhotic patients with ascites are complex, one has to consider many possibilities. Firstly, an apparent PEEPi may be due to a discrepancy between pleural and oesophageal pressure in the supine position, in which the present measurements were carried out. In fact, in this position oesophageal pressure may be higher than pleural pressure [36, 37]. However, this cannot explain the presence of a time lag between the beginning of the negative deflection in pleural pressure and the beginning of inspiratory flow. Secondly, contraction of abdominal muscles during expiration may result in an apparent PEEPi or contribute to it [17]. This mechanism did not appear to contribute substantially to the production of PEEPi in the present patients, as they did not show an increase in gastric pressure on expiration (fig. 1).

Thirdly, high intra-abdominal pressure causes pleural pressure to be high at end-expiration (fig. 4), and this in turn can determine an early closure of the airways. As a consequence, the alveoli of the dependent lung regions do not empty during expiration and a positive pressure remains in them at end-expiration. This hypothesis is supported by the close interrelationship between changes in PEEPi, the amount of fluid removed and $P$ pl,EE (figs. 5a, 5c and 6): the larger the amount of fluid removed, the greater the reduction in $P$ pl,EE and PEEPi, and the lower the $P \mathrm{pl}, \mathrm{EE}$, the lower the PEEPi. Thus, we think that increased abdominal pressure played a major role in determining the presence of PEEPi. However, other mechanisms, such as mechanical com- pression of the small airways by dilated blood vessels and interstitial oedema, cannot be ruled out [35].

Finally, the observation that LVP had small effects on respiratory mechanics when less than 5-6 L of ascites was removed (fig. 5a-c), suggests that a substantial reduction of respiratory load can be achieved only if large volumes of ascites are subtracted. This observation may have importance in the clinical management of ascitic patients.

In conclusion, in supine cirrhotic patients, tense ascites determines an overload for inspiratory muscles due both to a high lung elastic load and the presence of positive end-expiratory alveolar pressure. Large volume paracentesis unloads the inspiratory muscles and decreases their activation, thus significantly improving the respiratory function. Decreased inspiratory muscle strength, possibly determined by the metabolic alterations characteristic of liver cirrhosis, may be present in some patients in the sitting position and is not modified by large volume paracentesis.

\section{References}

1. Abelmann WH, Frank NR, Gaensler EA, Cugell DW. Effects of abdominal distension by ascites on lung volumes and ventilation. Arch Intern Med 1954; 93: 528-540.

2. Berkowitz KA, Butensky MS, Smith RL. Pulmonary function changes after large volume paracentesis. Am J Gastroenterol 1993; 88: 905-907.

3. Angueira CE, Kadakia SC. Effects of large-volume paracentesis on pulmonary function in patients with tense cirrhotic ascites. Hepatology 1994; 20: 825-828.

4. Hanson CA, Ritter AB, Duran W, Lavietes MH. Ascites: its effect upon static inflation of the respiratory system. Am Rev Respir Dis 1990; 142: 39-42.

5. Conn HO. Hepatic encephalopathy. In: Schiff L, Schiff ER, eds. Diseases of the Liver. Philadelphia, J.B. Lippincott Co., 1993; pp. 1036-1060.

6. American Thoracic Society. Chronic bronchitis, asthma and pulmonary emphysema: a statement by the committee on diagnostic standards for nontuberculous respiratory disease. Am Rev Respir Dis 1962; 85: 762-768.

7. Pugh RNH, Murray-Lyon IM, Daewson JL, Pietroni MC, Williams R. Transection of the oesophagus for bleeding oesophageal varices. Br J Surg 1973; 60: 646-649.

8. Arroyo V, Gines P, Planas R, Planés J, Robés J. Paracentesis in the management of cirrhotic ascites. In: Epstein M, ed. The Kidney in Liver Disease. Baltimore, William \& Wilkins, 1988; pp. 578-592.

9. European Coal and Steel Community. Standardization of lung function tests. Bull Eur Physiopathol Respir 1983; 19 (Suppl. 5): 1-95.

10. Konno K, Mead J. Measurements of the separate volume changes of rib cage and abdomen during breathing. J Appl Physiol 1967; 22: 407-422.

11. Agostoni E, Rahn H. Abdominal and thoracic pressures at different lung volumes. J Appl Physiol 1960; 15: 1087-1092.

12. Duranti R, Misuri G, Gorini M, Goti P, Gigliotti F, Scano G. Mechanical loading and control of breathing in patients with severe chronic obstructive pulmonary disease. Thorax 1995; 50: 127-133.

13. Miller JM, Moxham J, Green M. The maximal sniff in the assessment of diaphragm function in man. Clin Sci 1985; 69: 91-96. 
14. Frank NR, Mead J, Ferris BG Jr. The mechanical behaviour of the lungs in healthy elderly persons. J Clin Invest 1957; 36: 1680-1687.

15. Haluszka J, Chartrand DA, Grassino AE, Milic-Emili J. Intrinsic PEEP and arterial $P_{\mathrm{CO}_{2}}$ in stable patients with chronic obstructive pulmonary disease. Am Rev Respir Dis 1990; 141: 1194-1197.

16. Dal Vecchio L, Polese G, Poggi R, Rossi A. "Intrinsic" positive end-expiratory pressure in stable patients with chronic obstructive pulmonary disease. Eur Respir $J$ 1990; 3: 74-80.

17. Ninane V, Yernault JC, De Troyer A. Intrinsic PEEP in patients with chronic obstructive pulmonary disease: role of expiratory muscles. Am Rev Respir Dis 1993; 148: 1037-1042.

18. Ginès P, Titóo L, Arroyo V, Planas R, et al. Randomized comparative study of therapeutic paracentesis with and without intravenous albumin in cirrhosis. Gastroenterology 1988; 94: 1493-1502.

19. Berry MJ, McMurray RG, Katz VL. Pulmonary and ventilatory responses to pregnancy, immersion and exercise. J Appl Physiol 1989; 66: 857-862.

20. Heinemann HO, Emirgil C, Mijnssen JP. Hyperventilation and arterial hypoxemia in cirrhosis of the liver. Am J Med 1960; 28: 239-246.

21. Stanley NN, Salisbury BG, McHenry LR Jr, Cherniack NS. Effect of liver failure on the response of ventilation and cerebral circulation to carbon dioxide in man and in the goat. Clin Sci Mol Med 1975; 49: 157-169.

22. Augusti AGN, Roca J, Bosch J, Rodriguez-Roisin R. The lung in patients with cirrhosis. J Hepatol 1990; 10: 251-257.

23. Rodriguez-Roisin R, Agusti A, Roca J. The hepatopulmonary syndrome: new name, old complexities. Thorax 1992; 47: 897-902.

24. Hourani JM, Bellamy PE, Tashkin DP, Batra P, Simmons MS. Pulmonary dysfunction in advanced liver disease: frequent occurrence of an abnormal diffusing capacity. Am J Med 1991; 90: 693-700.

25. Prezant DJ, Aldrich TK, Karpel JP, Lynn RI. Adaptations in the diaphragm's in vivo force-length relationship in patients on continuous ambulatory peritoneal dialysis. Am Rev Respir Dis 1990; 141: 1342-1349.

26. Gilroy RJ, Mangura BT, Lavietes MH. Rib cage and abdominal volume displacements during breathing in pregnancy. Am Rev Respir Dis 1988; 137: 668-672.

27. Siafakas NM, Argyrakopoulos T, Andreopoulos K, Tsoukalas G, Tzanakis N, Bouros N. Respiratory muscle strength during continuous ambulatory peritoneal dialysis (CAPD). Eur Respir J 1995; 8: 109-113.

28. Contreras G, Gutierrez M, Beroiza T, et al. Ventilatory drive and respiratory muscle function in pregnancy. $A m$ Rev Respir Dis 1991; 144: 837-841.

29. Zocchi L, Garzaniti N, Newman S, Macklem PT. Effect of hyperinflation and equalization of abdominal pressure on diaphragmatic action. J App Physiol 1987; 62: $1655-1664$

30. Conn HO, Atterbury CE. Cirrhosis. In: Schiff L, Schiff ER, eds. Diseases of the Liver. Philadelphia, J.B. Lippincott Co., 1993; pp. 875-934.

31. Sharp JT, Henry JP, Sweany SK, Meadows WR, Petras RJ. The total work of breathing in normal and obese men. J Clin Invest 1964; 43: 728-739.

32. Rochester DF, Enson Y. Current concepts in the pathogenesis of the obesity hypoventilation syndrome. Am J Med 1974; 57: 402-420.

33. McIlroy MB, Butler J, Finley T. The effect of chest strapping in normal subjects. Fed Proc 1959; 18: 102.

34. Caro CG, Butler J, Dubois AB. Some effects of restriction of chest cage expansion on pulmonary function in man: an experimental study. J Clin Invest 1960; 39: 573-583.

35. Ruff F, Hughes JMB, Stanley N, et al. Regional lung function in patients with hepatic cirrhosis. J Clin Invest 1971; 50: 2403-2413.

36. Mead J, Gaensler EA. Esophageal and pleural pressures in man, upright and supine. J Appl Physiol 1959; 14: 81-83.

37. Knowles JH, Hong SK, Rahn H. Possible errors using esophageal balloon in determination of pressure-volume characteristics of the lung and thoracic cage. J Appl Physiol 1959; 14: 525-530. 